Article

\title{
Quantifying Freshwater Mass Balance in the Central Tibetan Plateau by Integrating Satellite Remote Sensing, Altimetry, and Gravimetry
}

\author{
Kuo-Hsin Tseng ${ }^{1,2,3, *}$, Chung-Pai Chang ${ }^{2}$, C. K. Shum ${ }^{4,5}$, Chung-Yen Kuo ${ }^{6}$, Kuan-Ting Liu ${ }^{1}$, \\ Kun Shang ${ }^{4}$, Yuanyuan Jia ${ }^{4}$ and Jian Sun ${ }^{4}$ \\ 1 Department of Civil Engineering, National Central University, 32001 Taoyuan, Taiwan; \\ 103322086@cc.ncu.edu.tw \\ 2 Center for Space and Remote Sensing Research, National Central University, 32001 Taoyuan, Taiwan; \\ cpchang@csrsr.ncu.edu.tw \\ 3 Institute of Hydrological and Oceanic Sciences, National Central University, 32001 Taoyuan, Taiwan \\ 4 Division of Geodetic Science, School of Earth Sciences, Ohio State University, Columbus, OH 43210, USA; \\ ckshum@osu.edu (C.K.S.); shang.34@osu.edu (K.S.); jia.102@osu.edu (Y.J.); sun.1091@osu.edu (J.S.) \\ 5 State Key Laboratory of Geodesy and Earth's Dynamics, Institute of Geodesy and Geophysics, \\ Chinese Academy of Sciences, Wuhan 43077, China \\ 6 Department of Geomatics, National Cheng-Kung University, 70101 Tainan, Taiwan; \\ Kuo70@mail.ncku.edu.tw \\ * Correspondence: khtseng@csrsr.ncu.edu.tw; Tel.: +886-3-4227151
}

Academic Editors: Cheinway Hwang, Wenbin Shen, Stéphane Calmant, Magaly Koch and Prasad S. Thenkabail Received: 29 February 2016; Accepted: 18 May 2016; Published: 24 May 2016

\begin{abstract}
The Tibetan Plateau (TP) has been observed by satellite optical remote sensing, altimetry, and gravimetry for a variety of geophysical parameters, including water storage change. However, each of these sensors has its respective limitation in the parameters observed, accuracy and spatial-temporal resolution. Here, we utilized an integrated approach to combine remote sensing imagery, digital elevation model, and satellite radar and laser altimetry data, to quantify freshwater storage change in a twin lake system named Chibuzhang Co and Dorsoidong Co in the central TP, and compared that with independent observations including mass changes from the Gravity Recovery and Climate Experiment (GRACE) data. Our results show that this twin lake, located within the Tanggula glacier system, remained almost steady during 1973-2000. However, Dorsoidong Co has experienced a significant lake level rise since 2000, especially during 2000-2005, that resulted in the plausible connection between the two lakes. The contemporary increasing lake level signal at a rate of $0.89 \pm 0.05 \mathrm{~cm} \cdot \mathrm{yr}^{-1}$, in a $2^{\circ}$ by $2^{\circ}$ grid equivalent water height since 2002 , is higher than the GRACE observed trend at $0.41 \pm 0.17 \mathrm{~cm} \cdot \mathrm{yr}^{-1}$ during the same time span. Finally, a down-turning trend or inter-annual variability shown in the GRACE signal is observed after 2012, while the lake level is still rising at a consistent rate.
\end{abstract}

Keywords: Tibetan Plateau; water mass balance; remote sensing

\section{Introduction}

The Tibetan Plateau (TP), serves as the "water tower" of Asian countries, accommodating 1055 alpine lakes with a total lake area equals to $41,831.7 \mathrm{~km}^{2}$ [1]. It also hosts approximately 36,000 glaciers spread across the northern (Tianshan ranges), central (Tanggula mountain), and southern (Himalaya ranges) parts of the region. The TP serves as the origin of several major river systems in East and South Asia, such as the Yangtze, Yellow, Mekong (also called Lancang in the upper section), Brahmaputra (Yaluzangbu), and Ganges River. The TP is a focal point of a wide range of research interests, covering 
atmosphere, cryosphere, hydrosphere, and lithosphere. The reason it is so engaged in geoscience is not only because of its unique geographical formation, with an average altitude over $4000 \mathrm{~m}$ formed by geological processes, but also its sensitivity to the anthropogenic activities and climate change [2].

The freshwater storage in glaciers apparently experienced an accelerated loss arguably due to the contemporary climate-warming episode in recent years. From remote sensing and in situ records, the rising rate of temperature over the entire TP is estimated at $0.01-0.05{ }^{\circ} \mathrm{C} \cdot \mathrm{yr}^{-1}$ [3-5] during the past 2-3 decades. Rapid glacier depletion, along with permafrost degradation also caused by temperature changes, indicates that the water in a frozen state changes tremendously over the TP. This warming procedure has caused many glacier-fed lakes to increase, especially over the last two decades. Thus, monitoring of lake dynamics is important and can be used as a proxy to study the amount of melting ice from thinning glaciers and/or due to changing or recently increased patterns of precipitation [6]. However, most of studies [7] conducted so far either focused on lake extent change, or short-term water level change using limited sensors. These limitations, either spatial or temporal, have made the exact quantification of water storage changes difficult. Hence, other supplemental observation is desirable to study long-term lake volume changes.

The observation of freshwater storage change has been realized by satellite radar altimetry, laser altimetry, optical remote sensing, and gravimetry approaches. However, each spaceborne sensor has its own advantages and limitations in spatial-temporal resolution. For example, radar altimetry satellites, such as Jason-2 (Envisat), has a 10 (35) day repeat cycle and weather-free capability to measure surface elevation, but its large footprint (3-5 km in radius), customized for open ocean study, hinders the retrieval of surface heights within steep and rugged terrain. The radar waveform, contaminated by a mixture of surface types, is still a challenge for current waveform retracking technologies. Another major limitation in radar altimetry are the large spatial gaps between ground tracks. The interval of parallel ground tracks is about $60 \mathrm{~km}$ for Envisat and $250 \mathrm{~km}$ for Jason-2 at the latitude of the TP. Hence, A large number of lakes within the TP cannot be monitored. The advantage of laser altimetry missions, such as the Ice, Cloud, and land Elevation Satellite (ICESat), a mission dedicated to cryosphere studies, is the usage of laser photons to detect the height within small footprints ( $70 \mathrm{~m}$ in radius). Unfortunately, the mission had just been operated in campaign mode with a short time span in 2003-2009. The next opportunity would be the ICESat-2 mission scheduled for launch in 2018. Finally, The Gravity Recovery and Climate Experiment (GRACE) [8] provides measurements of time-variable gravity that can be converted to mass redistribution. However, GRACE has a coarse resolution of a few hundred kilometers that makes lake studies difficult [9].

A potential solution to fill spatial-temporal gaps left by the instruments mentioned above is an integration of multiple sensors and products, such as combining altimetry and synthetic aperture radar (SAR) images [10], or relating water level with extent/volume by coincident altimetry and high-resolution satellites images [11]. Optical satellite remote sensing can effectively assist the monitoring of water storage changes. For a relative large lake such as Chibuzhang Co and Dorsoidong Co, mid-resolution remote sensing images may by sufficient to detect lake surface variations. For example, since the 1970s, Landsat series provide 16-day revisit cycle with $30 \mathrm{~m}$ medium resolution raster file with multispectral information. It could further compose false-color images to analyze land use/land cover (LULC). The Thematic Imagery-Altimetry System (TIAS) proposed in [12] intended to estimate water level change using historical Landsat imageries in Lake Mead, NV, USA. They exploited historical Landsat imageries to extend the time series of water level towards multi-decadal coverage, longer than a connection of operated and existing altimetry satellites. They applied the concept of hypsometry (reconstruction of contour from instant outline of a waterbody) to compute the elevation of the water level by overlapping water outline with a digital elevation model. The application of TIAS at Lake Mead, with relatively steep terrain, has accuracy at $0.85 \pm 0.63 \mathrm{~m}$ as compared with gauge data. Based on their simulation of error budget, the accuracy at a terrain slope of $<20^{\circ}$ and a number of shoreline pixels around 7000, similar to the geographical setup in Chibuzhang-Dorsoidong Co, the 
accuracy could reach the $<0.5 \mathrm{~m}$ level. Hence, this study intends to examine the applicability of the TIAS at these alpine lakes for investigation of water storage changes in the last 40 years.

This study utilizes historical archives of Landsat images, including multiple sensors onboard Landsat-1/-2/-5/-7/-8. The images are intersected with the Shuttle Radar Topography Mission (SRTM) digital elevation model (DEM) to collect height information along the shoreline of each studied lake. The lake level is then estimated by locating the most probable value of height samples through the Generalized Extreme Value (GEV) fitting procedure. The lake level change since 1970s is unveiled by using this TIAS approach. As further combined with SRTM, the water volume is calculated by integrating column water in each SRTM grid. The result is finally compared with GRACE gravity anomaly, with a purpose to infer a broader scale mass change within a few hundreds of kilometers. Other factors such as precipitation that potentially disturb water budget is also inspected, referring to the Tropical Rainfall Measuring Mission (TRMM) data.

An introduction of study area, the central TP covering this twin lake and Tanggula glacier system is given in Section 2. The data utilized in this study, including satellite altimetry (Envisat, Jason-2, and ICESat), optical remote sensing (Landsat), radar/microwave radiometry (TRMM), and gravimetry (GRACE) are described in Section 3. Sections 4 and 5 include a validation of TIAS water level estimates, and discuss an integrated observation of water mass change estimated by TIAS and GRACE data. Finally, the conclusion of the study is reported in Section 6.

\section{Study Area}

The twin lakes, named Chibuzhang Co (Co means lake in Tibetic) and Dorsoidong Co, are located in the central TP (Figure 1). Each lake varied independently in earlier years and became interlinked in the mid-2000s [13]. Chibuzhang Co is a glacier-fed lake with water sources from glaciers surrounding Gêladaindong Mountain, located $50 \mathrm{~km}$ eastward. Dorsoidong Co is also a glacier-fed lake that is a bit smaller than Chibuzhang [13]. Water sources filling into Dorsoidong Co are mainly from the Purog Kangri Mountain, considered to be the third largest glacier in the world, after the polar regions, located northwest of the lake in $\sim 50 \mathrm{~km}$ (Figure 1). There are several other adjacent lakes near the Tanggula Mountains, including Yagen, Laorite, Botao, and many other lakes with smaller areas. Here we focus on this twin lake with a combined surface area greater than $1000 \mathrm{~km}^{2}$. According to [7], it is suggested that $53 \%$ of the total lake area is in charge of about $61 \%$ of mass change over the entire inner TP (ITP). Hence, we assume that this twin lake is large enough to represent a considerable part of mass contribution in GRACE signal.

The TP is divided into the North and South Tibetan blocks by the Tanggula Mountains, which is a fold belt representing a late Jurassic-early Cretaceous suture belt. The belt is no longer active according to recent GPS measurements [14]. Tanggula Mountains also served as geographical boundary between the continental climate and the summer Indian monsoon over the plateau [15]. The northern part of the range is subject to continental air masses and the southern part is affected by Indian summer monsoon. The tallest peak, Gêladaindong Mountain, with an elevation of $6621 \mathrm{~m}$ above sea level, is also the headwater of Yangtze River. The average temperature of the Tanggula Mountains is about $-5^{\circ} \mathrm{C}$ during the year. In summer, the temperature reaches over $20^{\circ} \mathrm{C}$, while in winter it drops below $-15^{\circ} \mathrm{C}$ but, in the area over $5000 \mathrm{~m}$, it remains cold year round [16]. The snow and hailstones in alpine areas indicate conditions favorable for glacier development. However, due to the climate change that caused a global warming pattern, temperature over the plateau exhibits an increasing trend at about $0.016{ }^{\circ} \mathrm{C} \cdot \mathrm{yr}^{-1}$ [17]. Most glaciers in Tanggula Mountains started to retreat since the 1960s. Previous study showed that a general retreat rate in glaciers near Gêladaindong is about $1.29 \mathrm{~km}^{2} \cdot \mathrm{yr}^{-1}$ during 1969-2002 [18]. Hence, several adjacent lakes had been observed clear increasing in water volume. Therefore, it is quite a critical issue to accurately monitor and quantify glacier depletion and lake level rise in this area. 

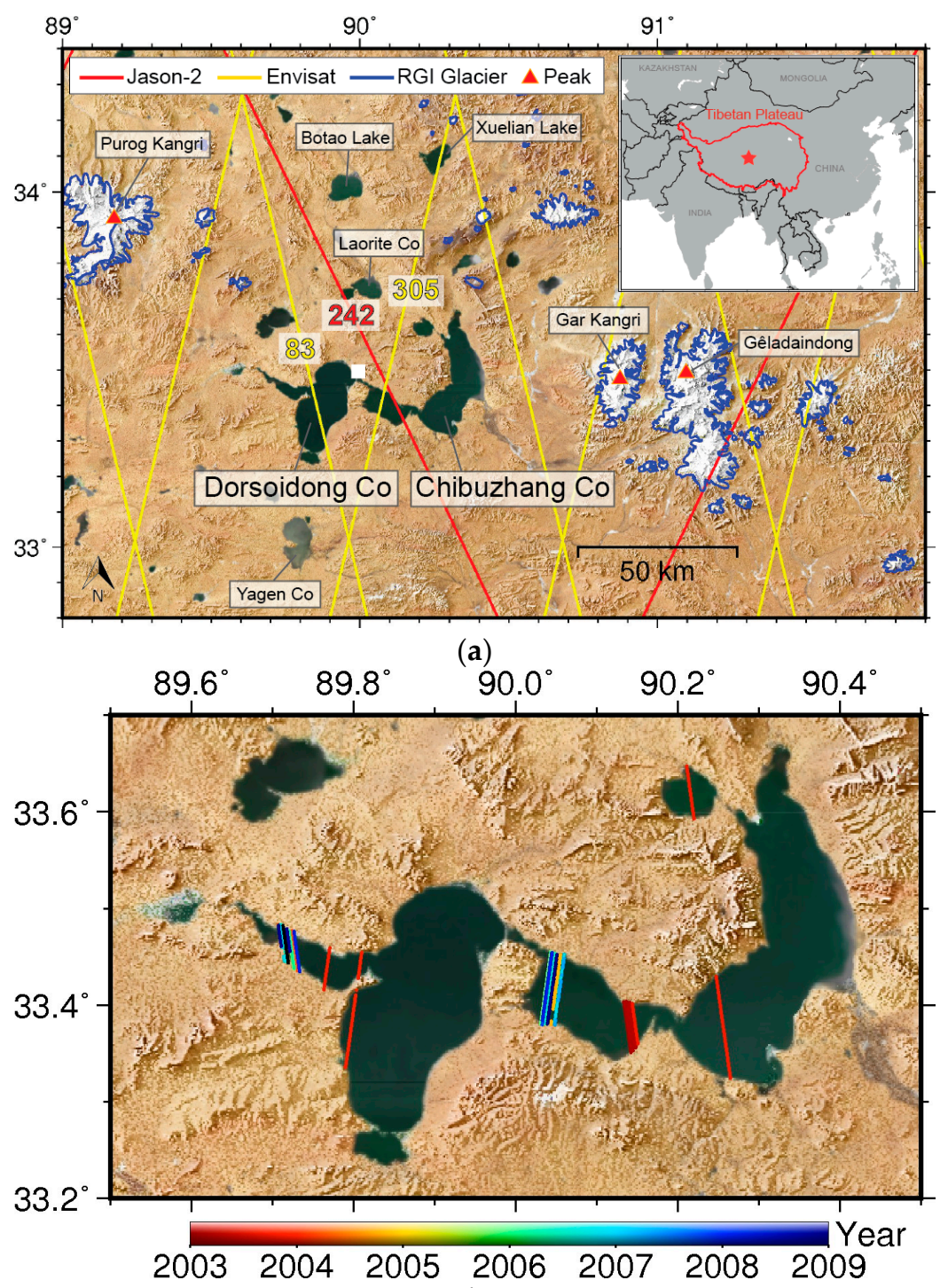

(b)

Figure 1. (a) Locations of Chibuzhang Co, Dorsoidong Co, and Tanggula glacier system in the central TP. The boundary of TP and relative location of study site is displayed in the overview map. Yellow and red lines in the main figure are Envisat and Jason-2 ground tracks, respectively. White square near $33.5^{\circ} \mathrm{N}$ and $90^{\circ} \mathrm{E}$ is the center of GRACE $2^{\circ} \times 2^{\circ}$ grid. Blue outline of glaciers is from the Randolph Glacier Inventory (RGI) [19]; and (b) a blow up view of this twin lake, with ICESat actual ground tracks color-coded by year of data, 2003-2009. The passes are mainly centered in western basin of each lake.

\section{Satellite Data and Processing Method}

\subsection{Radar and Laser Altimetry}

In this study, both radar and laser altimetry data products are used to estimate lake level change in this twin lake system. Satellite radar altimetry is classically used to observe surface height from active remote sensing approach, especially for open ocean. It is basically to estimate surface heights by timing the transmission of electromagnetic pulses generated by an onboard altimeter. The duration of transmission is the two-way travel time between emission and reception of the signal reflected from the nadir surface. After appropriate corrections for medium terms (GPS ionosphere and dry/wet troposphere delay models), geophysical terms (solid Earth tide, pole tide), and hardware (e.g., ultra stable oscillator, USO), surface height with respect to a reference ellipsoid is approximated by 
subtracting the measured range from the orbital altitude. After that, an extra step called radar waveform retracking is executed to fine-tune the measured ranges (its impact is at least a few centimeters) by tracing the midpoint of the leading edge in waveforms coming from a variety of surface types. Waveform retracking is replaced the classic Brown model [20], which is more suited to process the waveforms returned from open ocean with statistical parameters. Empirical waveform retrackers were also invented to analyze radar echoes from ice sheet [21,22], ice floes [23] and, more recently, coastal areas [24], inland waters [25-28], and even for bare land [29]. The accuracy of satellite radar altimetry is generally ranging from the $5 \mathrm{~cm}$ level for open ocean [30], to the 10-40 $\mathrm{cm}$ level for coastal and large inland waters [24,31], and the 30-90 cm level for narrow rivers [32,33].

Envisat was launched by European Space Agency in March 2002 and terminated in April 2012. It worked in a sun-synchronous orbit with a 35-day revisit period. It carried a dual-frequency radar altimeter operating in $\mathrm{Ku}$ and $\mathrm{S}$ band with an intention to measure satellite-Earth distance and to mitigate ionosphere disturbance at the same time [34]. However, the ionospheric effect, quantified as the total electron content (TEC) that caused transmission delay, is better mapped by worldwide GNSS ground stations. Hence the Global Ionosphere Map (GIM) released by NASA/JPL has been extensively used as a reference to correct time delay and ultimately the lengthened distance. Similarly, the tropospheric correction has adopted global model provided by the European Centre for Medium-Range Weather Forecasts (ECMWF) instead of onboard radiometer. The altimeter data used in this study is the Geophysical Data Record (GDR, version 2.1) released by CNES Archiving, Validation, and Interpretation of Satellite Oceanographic data (AVISO) service. We utilized ICE-1 retracking algorithm provided by AVISO with a time span covering regular operation mode, 2002-2012 (cycle 6-93). ICE-1/ICE-2 algorithms developed for analyzing specular shape of waveform over ice sheet are applicable for lake observations with similar waveform patterns [35-38]. As shown in Figure 1, Envisat had two passes, \#83 and \#305, with crossovers in study site. However, because of an USO issue not recoverable by post processing, pass \# 83 had only three usable cycles at this location during entire mission span. Hence we chose only pass \#305 and compared with other data sources.

The Ocean Surface Topography Mission (OSTM)/Jason-2 is a follow-on mission of two successful predecessors, TOPEX/Poseidon and Jason-1 [39]. It was launched in June 2008 and still in a normal condition to present. It works in a non-sun-synchronous orbit with approximate 10-day revisit period to better solve short-term ocean surface changes. It carries a solid-state Poseidon-3 dual-frequency altimeter working in $\mathrm{Ku}$ and $\mathrm{C}$ bands. We utilized GDR version T (JA2_GPS_2PTP) provided by AVISO with the time span covering cycle 1 in July 2008 to cycle 270 in November 2015. Similar ICE retracking algorithm was used to extract water surface height at pass \#242 specified in Figure 1. For both altimeters we first created a water mask $\sim 1 \mathrm{~km}$ away from the shoreline to prevent potential land contamination. A threshold of backscattering coefficient at $15 \mathrm{~dB}$, indicating a returned signal from a smoother surface in the radar perspective, was selected to collect water measurements. This threshold was chosen based on an examination of points falling within the water mask.

Laser altimetry used here is the ICESat mission operated from 2003 to 2009. Principally similar to radar altimetry, one calculates the timing between transmissions of three lasers, in wavelengths of 1064 $\mathrm{nm}$ and $532 \mathrm{~nm}$, to profile vertical distribution all the way from cloud top to the Earth's surface [40]. By applying the "photon counting" technique [41] for surface detection, the elevation of nadir surface is estimated. However, due to a pump diode failure soon after launch, ICESat could not be operated continuously; thus, a campaigned mode was switched to alternatively extend the mission life. It only worked in a 33-day to 56-day campaigns mostly in February-March/May-June/October-November during 2003-2009. The measurement at timing of season transitions is still valid to study gradual changes in cryosphere and other phenology with inter-annual cycle. The ICESat data used here is released by the NASA's earth observing system clearing house (ECHO) online portal [42]. Altimetry land product number 14 (GLA14, release-33) was used to extract the high-rate $(40 \mathrm{~Hz})$ elevation data. 


\subsection{Optical Remote Sensing and Water Detection}

Optical remote sensing satellites have been used extensively to retrieve surface reflectance and radiative information for quantification of geophysical parameters. For optical satellite images, we used Landsat-1/-2/-5/-7/-8 to extract water area by using multispectral analysis. Landsat-1 launched by NASA in 1972 was originally named ERTS-1 (Earth Resources Technology Satellite). It carried a multispectral scanner (MSS) operating in green, red, and two near-infrared bands. It worked in the Worldwide Reference System-1 (WRS-1) path/row system with an 18-day repeat cycle. Landsat-2 launched in 1975 carried a similar MSS instrument ranging from 500 to $1100 \mathrm{~nm}$. The original resolution of MSS pixel was $79 \times 57 \mathrm{~m}$, but it was later resampled to $60 \mathrm{~m}$. Although the number of bands in MSS was less than the following Thematic Mapper (TM) and Enhanced Thematic Mapper Plus (ETM+) flying onboard Landsat successors, it contained two essential bands, green and near-infrared, for classification of water bodies. Landsat-5 covered from 1984 to 2013. It carried the TM operated in seven bands ranging between $450 \mathrm{~nm}$ and $2350 \mathrm{~nm}$. In 1999, Landsat-7 was launched with the ETM+ similar to TM except for an extra panchromatic band at $15 \mathrm{~m}$ resolution. Finally, Landsat- 8 was launched lately in 2013 with an onboard Operational Land Imager (OLI), sensing wavelengths between $430 \mathrm{~nm}$ and $2290 \mathrm{~nm}$. While combined with the thermal infrared sensor (TIRS), the spectral coverage is up to $12,510 \mathrm{~nm}$.

The combined time span of a suite of Landsat imageries allows us to observe the twin lake from 1973 to present. With a median spatial resolution at $60 \mathrm{~m}$ for Landsat-1/-2 and $30 \mathrm{~m}$ for the rest, they have a nominal revisit cycle at 16-18 days. For spectral resolution, Landsat imagery covering from visible light to infrared band is sufficient to detect water existence. All the images are in GeoTiff format and are available at no cost from the U.S Geological Survey (USGS) EarthExplorer website [43] The WRS path/row at this twin lake is frame 139/37.

In this study, all the available raw images (level 1) were first gathered and then appropriate images with less cloud cover along shoreline were selected to extract water surface information. In the end, a total of 325 images for Chibuzhang Co and 329 images for Dorsoidong Co were used in the following TIAS computation. All the radiometric information stored as digital numbers (DN) in each pixel was first converted into the top-of-atmosphere reflectance (ToA) for all the images collected. The conversion addresses effects caused by varying sunlight angle and distance, as shown in Equations (1) and (2) [44]:

$$
\begin{gathered}
L_{\lambda}=\text { gain } \times D N+\text { bias } \\
\rho_{\lambda}=\pi \times L_{\lambda} \times \operatorname{ESUN}_{\lambda} \times \cos \theta s
\end{gathered}
$$

where $L_{\lambda}$ is the cell value as radiance; $D N$ is the cell value digital number; gain is the gain value for a specific band; bias is the bias value for a specific band; $\rho_{\lambda}$ is the unitless planetary reflectance; $d$ is the Earth-Sun distance, in astronomical units; $E S U N_{\lambda}$ is the mean solar exoatmospheric irradiances; and $\theta_{S}$ is the solar zenith angle.

For Landsat-8 images, the conversion follows equations shown below [45]:

$$
\rho_{\lambda}^{\prime}=M_{\rho} Q_{c a l}+A_{\rho}
$$

where $\rho_{\lambda}{ }^{\prime}$ is the ToA planetary reflectance (without correction for solar angle); $M_{\rho}$ is the band-specific multiplicative rescaling factor; $A_{\rho}$ is the band-specific additive rescaling factor; and $Q_{c a l}$ is the quantized and calibrated standard product pixel values $(D N)$. The next step to correct ToA reflectance for the sun angle is expressed as:

$$
\rho_{\lambda}=\rho_{\lambda}^{\prime} / \sin \left(\theta_{S E}\right)
$$

where $\rho_{\lambda}$ is the ToA planetary reflectance and $\theta_{S E}$ is the local sun elevation angle.

Since the cloud and hazy images were removed during the first step of data collection, the atmospheric correction was not applied further to the ToA in this study, for simplification. It is noted that the procedure without considering atmosphere and aerosol condition may cause an error of $5 \%$, 
for example, using similar method for glacier detection [46]. There are several approaches developed to classify water surface from remote sensing images [47]. These methods can be divided into two types: supervised and unsupervised. Supervised classification requires a setup of training points based on a priori information, and the algorithm depends highly on the accuracy of training input. It usually requires trial-and-error iteration to improve the classification accuracy, while the training sample could not be used across images most of the time. For unsupervised methods, they can be further categorized as statistical algorithms and threshold methods. Statistical approaches consider the degree of uniqueness for each pixel and classified them into different clusters. Threshold methods set up a boundary in band combinations to distinguish the target from original images. In this study, the Modified Normalized Difference Water Index (MNDWI) [48] utilizing an unsupervised threshold approach was used. MNDWI is a modification of Normalized Difference Water Index (NDWI) [49] to improve the distinguishing result between water and built-up land. The equation of MNDWI is given in Equation (5), which is derived from a combination of the green and mid-infrared bands.

$$
M N D W I=(G-M I R) /(G+M I R)
$$

where $G$ represents green band in visible light and MIR is the mid-infrared band.

Since the bandwidth and band center has a bit shift across Landsat optical sensors, a selection of band and customized threshold setup was used, as given in Table 1. Once the MNDWI of each image composed, a thresholding procedure was applied to divide each pixel into water or non-water group. The threshold was determined by visual inspection of the water outline and comparison with nature/false color images.

Table 1. Band selection for Landsat series to compute MNDWI and threshold used to distinguish water while index value $>$ threshold.

\begin{tabular}{cccccc}
\hline Landsat \# (Sensor) & $\mathbf{1}$ (MSS) & $\mathbf{2}$ (MSS) & $\mathbf{5}$ (TM) & $\mathbf{7 ~ ( T M ) ~}$ & $\mathbf{8}$ (OLI) \\
\hline Green Band & 4 & 4 & 2 & 2 & 3 \\
MIR Band & 7 & 7 & 5 & 5 & 6 \\
Index Threshold & 0.4 & 0.4 & 0.2 & 0.2 & 0.4 \\
\hline
\end{tabular}

\subsection{From Water Area to Water Level Estimate}

The TIAS system proposed in [12] is to approximate lake level by collecting elevation information at the intersection of remote sensing imageries and a DEM. It picks pixels along the shoreline of the extracted water body and obtains elevation information from the co-registered DEM. The maximum likelihood estimate of water level can be found from a cluster of height "samples". The workflow of TIAS has been elaborated in [12] and will be briefly described in this section.

As illustrated in Figure 2, we first obtained the Shuttle Radar Topography Mission version 3 (SRTM C-band V3 at 1 arcsec) DEM at the study site. However, the raw DEM cannot be directly used since the elevation over the water area is null. This is because radar signal could not penetrate liquid water while composing the DEM. Therefore, we applied an empirical method to replace water mask by extending lakeside terrain towards the lake center, assuming the land remained at a constant slope below the water surface. As shown in Figure 2a, the raw DEM has a constant elevation over lake, thus, we cannot attain the height while lake extent shrinks into the water mask. By utilizing a bilinear extrapolation for DEM modification [12], the height of the lake bottom, or simulation of lake bathymetry, is achieved, as displayed in the lower panel of Figure 2a. It is worth mention that this empirical approach may only be valid near the shore, say within a few tens of meters. A longer distance from the shoreline may result in large errors in the modified DEM due to invalid assumptions of a constant slope.

Next, we calculated the value of MNDWI by using Equation (5) to determine that each pixel is water or non-water by thresholding (Table 1). Panel b in Figure 2 is an example of an original natural 
color image and its classification result for watery areas. After extraction of the water outline from the classification, outline pixels are placed onto the modified DEM to find intersections. These DEM intersections, as displayed in panel c, become height samples of the lake at certain snapshots. It is emphasized that Figure $2 \mathrm{c}$ is an example of shoreline detection of the entire twin lake. For analysis in this study, the two lakes were separated for individual water level computation. Finally, these samples would form a histogram with a mean value and some noises due to DEM uncertainty and classification errors (see panel d). Thus, we could apply the GEV fitting function to locate the best estimate of height among these samples. We noticed that the elevation of SRTM V3 was based on the EGM96 geoid model instead of the most up-to-date EGM2008 or EIGEN6 references. However, because we focused on height change of water levels relative to a consistent reference, the accuracy of the absolute water level was not a concern in the analysis. For example, a deviation of the differences at mostly $<5 \mathrm{~cm}$ between EGM96 and EGM2008 in this twin lake was ignored.

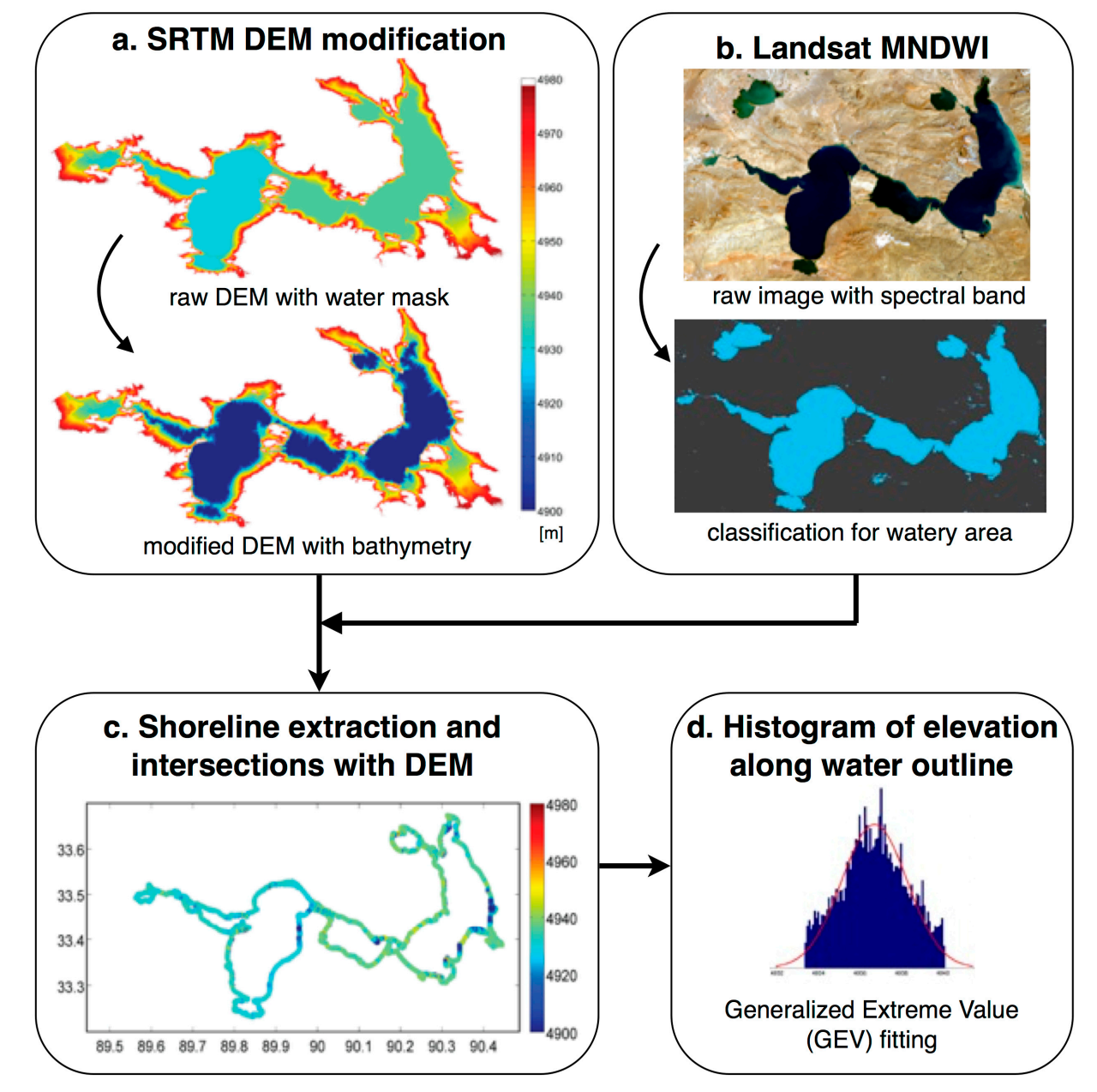

Figure 2. Workflow of TIAS at study site. (a) Modify raw SRTM DEM and fill in simulated lake bathymetry; (b) compute MNDWI from Landsat bands and use a threshold to separate water/non-water pixels; (c) extract water body outline and intersect with modified DEM to obtain height information; and (d) use Generalized Extreme Value fitting function of find the maximum likelihood estimate of height.

\subsection{GRACE Gravimetry Mission Data}

Satellite gravimetry is an emerging technique used to observe Earth's gravity field, including static and temporally changing terms. Understanding of the distribution/redistribution of Earth's mass is helpful for monitoring environmental changes due to anthropogenic or natural forcing. The 
Gravity Recovery and Climate Experiment (GRACE) [8] is a joint United States and German satellite mission that was lunched on 7 March 2002. The primary science objective is to measure the Earth's gravity field and its time variability with unprecedented accuracy. It is composed by two identical satellites about $220 \mathrm{~km}$ away. The K/Ka-band microwave ranging (KBR) system and GPS receivers as well as other on-board instruments are used to determine the orbit perturbation, mainly due to the inhomogeneous gravity field. The gravity anomaly can be derived from the distance change between the two satellite detected by the KBR system. GRACE is used to solve both the static and temporal gravity fields. The static gravity field is defined as the long-term average of the total mass measured by GRACE. Once the static gravity field has been determined, we assume some factors below the crust remains unchanged and all the atmospheric loading can be fully eliminated. The temporary gravity anomaly is finally calculated by subtracting the static model from the instant gravity field. However, the signal is not only surface water, but also soil moisture, groundwater mass change, and other mass redistribution near the Earth's surface, such as the post-glacial rebound.

The gravity field data from GRACE is decomposed as spherical harmonic (SH) coefficients, which can be approximately understood as sinusoidal functions in both zonal and longitudinal direction. Different wavelengths of spherical harmonics are expressed by degree and order, where degree/order is the index of spherical harmonics in zonal and longitudinal directions. The higher the degree/order, the more detailed feature can be explained. The original GRACE data inverted gravity field solution can reach about degree/order of 200 , but it is filled with noise in high frequencies. Thus, the standard release of GRACE data truncated the SH degree/order at 60-90 to solve the Earth's gravity field at a spatial resolution of $\sim 330 \mathrm{~km}$. Once we have the Earth's gravity anomaly, the mass can be converted into equivalent water height $(\mathrm{EWH})$ by analogy with the height of water per unit area. In this study, three monthly solutions (long enough in time to be consist of recognizable mass changes) provided by GeoForschungsZentrum (GFZ), Jet Propulsion Laboratory (JPL)/NASA, and the Center for Space Research (CSR, The University of Texas at Austin) were used and the C20 derived from Satellite Laser Ranging replaced those from GRACE [50]. A de-correlation process and $200 \mathrm{~km}$ Gaussian smoothing was also applied to reduce the north-south stripes of gridded EWH [51,52]. We subtracted the mean field (GIF48, [50]) from all GRACE monthly solutions to obtain the anomaly.

GRACE CSR/GFZ/JPL L2 Release 05 (RL05) monthly geopotential coefficients, covering from April 2002 to September 2015, were used here to estimate the total EWH over the study area. For each monthly solution, we first corrected the coefficients by replacing degree 1 [53], and zonal degree two [54] by using CSR's spherical harmonics in January 2006. We also corrected the glacial isostatic adjustment (GIA) IJ05_R2 model [55]. The spherical harmonic coefficients obtained from data agencies were converted into a $180 \times 180 \mathrm{EWH}$ grid and picked one cell $\left(2^{\circ}\right.$ by $\left.2^{\circ}\right)$ near $33.5^{\circ} \mathrm{N}$ and $90^{\circ} \mathrm{E}$. However, it is emphasized that the studied lake is still small relative to the grid size of GRACE monthly solution. The data used here is to reveal the neighboring condition of a combined geodynamical and hydrological evolution, including lake, glacier, soil moisture, groundwater, permafrost, and residual tectonic movement. There are even more uncertainties in the GRACE solution of sub-grid study, such as leakage problems, which require further study to piece together all temporal changes of abovementioned geophysical parameters in neighboring grids. A better approach to compare with GRACE may be the forward modeling [56], e.g., to set the contribution purely from lake area and convert the field into the spherical harmonic domain. After applying similar smoothing processes, as GRACE filtering and scaling, the signal would potentially be more realistic to the actual lake mass time series.

\subsection{TRMM Precipitation Record}

The Tropical Rainfall Measuring Mission (TRMM) jointly operated by NASA and JAXA offers unprecedented high-quality precipitation measurements over the tropical and subtropical regions [57]. It was launched in 1997 and started to deliver regular rainfall product since January 1998. It carries suites of instruments including a single-frequency precipitation radar (PR), TRMM microwave imager 
(TMI), clouds and the Earth's radiant energy sensor (CERES), visible and infrared scanning radiometer (VIRS), and lightning imaging sensor (LIS). The orbital design has an inclination of $35^{\circ}$ and low altitude at $350-400 \mathrm{~km}$. Along with wide-swath or conically scanning capability, these onboard sensors perform $250-880 \mathrm{~km}$ swath in cross-track and provide measurement within $50^{\circ} \mathrm{N}-\mathrm{S}$, covering $80 \%$ of the Earth's surface. Here we used the level-three monthly solution (product 3B43 version 7) of daily rainfall rate at $0.25^{\circ} \times 0.25^{\circ}$, to obtain a reference of mass anomaly potentially contributed by precipitation. We separated the study area roughly into two basins based on adjacent topography and water features: the left side for Dorsoidong Co covers a spatial box bounded $33^{\circ} \mathrm{N}-34^{\circ} \mathrm{N}$ and $89^{\circ} \mathrm{E}-90^{\circ} \mathrm{E}$, with 16 TRMM grids, while the right side for Chibuzhang Co covers a similar size of spatial box bounded $33^{\circ} \mathrm{N}-34^{\circ} \mathrm{N}$ and $90^{\circ} \mathrm{E}-91^{\circ} \mathrm{E}$. We used the entire 3B43 dataset spanning January 1998 to August 2015. For each month we took an arithmetic mean of 16 grids within the boundary to obtain the average rainfall rate in $\mathrm{mm} \cdot \mathrm{day}^{-1}$.

\section{Results}

\subsection{Validtion of Altimetry Results}

Temporal water level variation of Chibuzhang Co and Dorsoidong Co analyzed separately by TIAS is shown in Figure 3. In this figure, a $\pm 1 \sigma$ error bar at each point is plotted to show the uncertainty during the GEV fitting procedure. It is an indicator of combined error resulting from the relative height error of SRTM, water misclassification, and uncertainty due to Landsat's $30 \mathrm{~m}$ coarse resolution. This figure indicates two lakes varied independently before 2005, with a separation in height by about $8 \mathrm{~m}$. The independency can be traced back to June 1973 according to the first available snapshot taken by Landsat-1 MSS. Between 2000 and the end of 2005, the Dorsoidong Co experienced a sharp increasing in water level at $1.19 \mathrm{~m} \cdot \mathrm{yr}^{-1}$ while the Chibuzhang Co remained almost stable, with a gradually increasing rate at $0.06 \mathrm{~m} \cdot \mathrm{yr}^{-1}$, until 2005 when the two lakes became interlinked. After the interconnection, this twin lake appeared a combined rising trend at $0.40 \mathrm{~m} \cdot \mathrm{yr}^{-1}$ and $0.46 \mathrm{~m} \cdot \mathrm{yr}^{-1}$ as computed from Chibuzhang Co and Dorsoidong Co, respectively.

To validate the result given by TIAS, the time series is compared with other sensors, such as nominally more accurate ICESat estimates. ICESat finished a total of 35 usable passes in this twin lake: 20 in Chibuzhang Co and 15 in Dorsoidong Co (see Figure 1b). It is worth mentioning that since the ICESat data spanning before and after the linkage of these two lakes, passes in each lake should be treated individually to show the independent variation. To compare both loosely sampled time series, we selected ICESat points within \pm 5 days of TIAS solutions and assumed the water level had no change during such a short period. A temporal comparison between TIAS and ICESat results is shown in Figure 4a, in which the up-pointing triangle means ICESat measurement from Chibuzhang Co and down-pointing triangle means that from Dorsoidong Co. We see that both approaches have detected the disconnection until the end of 2005, while the lines and triangles are almost overlapped after 2007. The statistics of TIAS performance, while treating ICESat as reference data, is shown in Table 2. In this table, the number in each cell indicates root-mean-square of the difference (RMSD) and the Pearson's correlation coefficient (CC) between two sensors (format: RMSD/CC). The upper-right triangle numerates results from Chibuzhang Co and lower-left triangle is from Dorsoidong Co. According to Table 2, TIAS estimates correlate very well with ICESat measurements with a RMSD at $0.30 \mathrm{~m}$ and a CC at 0.90 . This accuracy level also matches well with the simulation provided by the original TIAS error analysis. 


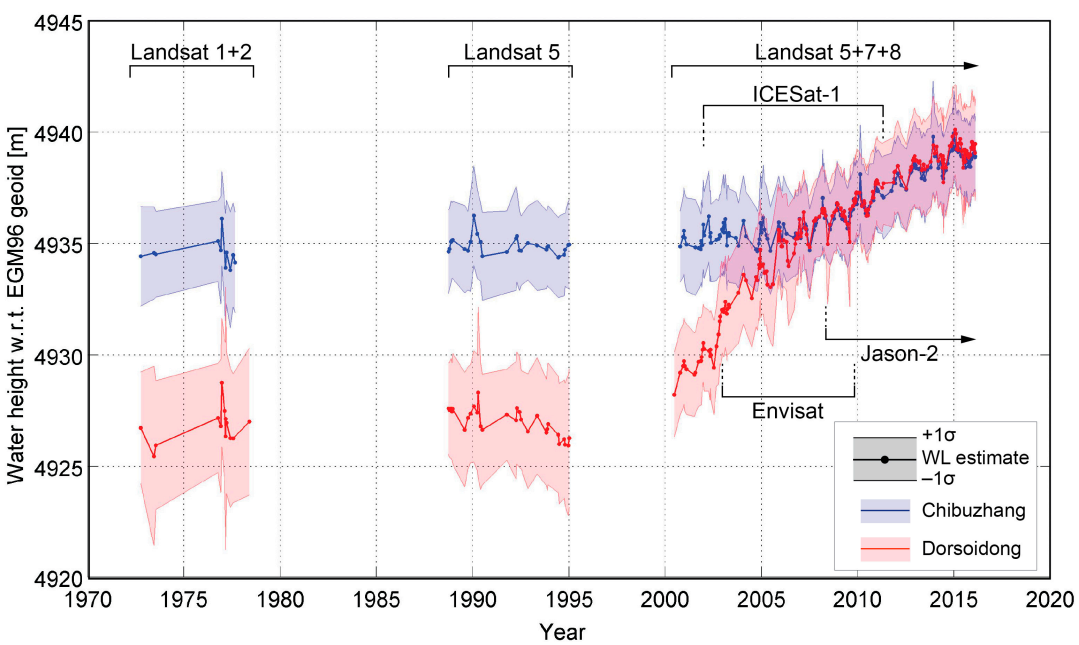

Figure 3. TIAS estimate of lake level in Chibuzhang Co (blue) and Dorsoidong Co (red). Color shades represent the respective time series $\pm 1 \sigma$ uncertainty. Temporal coverage of each sensor is annotated where the arrow means ongoing operation of Jason-2 and Landsat-7/-8.
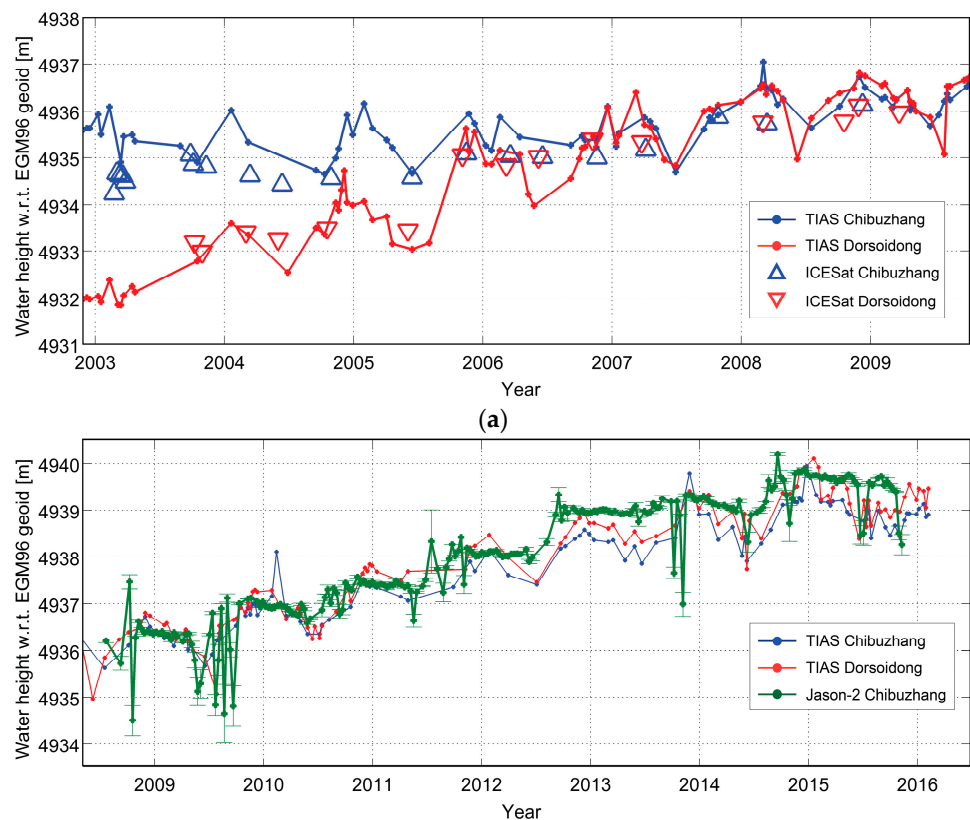

(b)

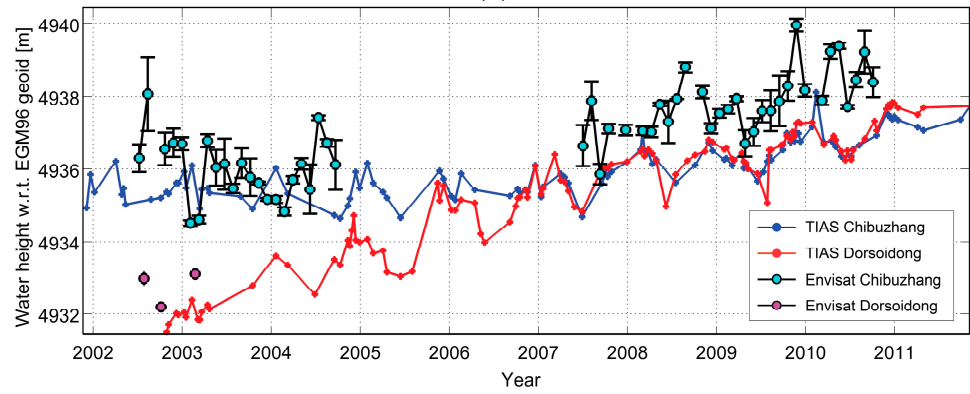

(c)

Figure 4. Time series between TIAS estimates (blue line for Chibuzhang Co and red line for Dorsoidong Co, respectively) and (a) ICESat measurements (blue triangle in Chibuzhang and red triangle in Dorsoidong); (b) Jason-2 (green lines); and (c) Envisat. 
Table 2. Comparison between sensors in the study area. Numbers in the matrix indicate root-mean-square of the difference (RMSD) in meters and Pearson's correlation coefficient (CC). The format is RMSD/CC.

\begin{tabular}{ccccc}
\hline Chibuzhang Dorsoidong & TIAS & ICESat & Jason-2 & Envisat \\
\hline TIAS & - & $0.30 / 0.90$ & $0.49 / 0.93$ & $1.02 / 0.65$ \\
ICESat & $0.42 / 0.98$ & - & $\mathrm{N} / \mathrm{A}$ & $0.54 / 0.93$ \\
Jason-2 & $0.48 / 0.94$ & $\mathrm{~N} / \mathrm{A}$ & - & $0.68 / 0.57$ \\
Envisat & N/A & N/A & N/A & - \\
\hline
\end{tabular}

For validation with other sensors, the rule of points selection, i.e., \pm 5 days within each pair of comparing points, is applied to all the following comparisons. Figure 4 also shows the water level variation from Jason-2 (Figure 4b) and Envisat (Figure 4c) with the same TIAS time series as background. In Figure 4b, we notice that Jason-2 is suffered from occasional jumps in water level, even though an increasing trend is clearly detected. The cause of these jumps, mainly due to irregular shapes of radar waveforms, is illustrated in Figure 5. Exemplified by the last cycle of this study (\#270), which has a clear drop in this time series of Figure $4 b$, a stake of waveforms along-track in the y-axis has a misaligned leading edge away from its nominal 32.5 tracking gate in the $\mathrm{x}$-axis. This pattern, due to various reasons, has led to several abnormal drops in height measurements. Hence, the difference between TIAS and Jason- 2 is a bit higher than ICESat, with RMSD at $0.49 \mathrm{~m}$ and CC at 0.93 . Since Jason-2 has no overlap with the ICESat time series, it is difficult to quantify the relative accuracy of Jason-2 itself.

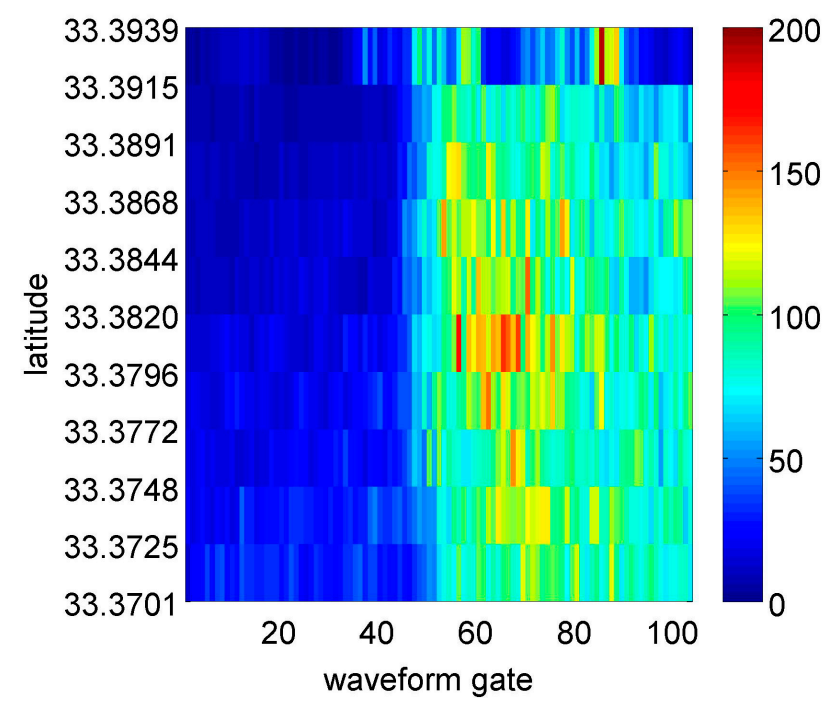

Figure 5. Sample of contaminated waveforms in Jason-2 data, demonstrated by the last cycle (\#270) used in this study. The x-axis is the waveform gate from 1 to 104 , and $y$-axis is the latitude of the ground track. Ten waveforms are stacked and color-coded in relative power units. The nominal tracking gate is 32.5 .

On the other hand, the comparison between Envisat and TIAS, as exhibited in Figure 4c, is much worse than others, where the RMSD and CC reaches only $1.02 \mathrm{~m}$ and 0.65 . It is suspected that Envisat pass \#305, as shown in Figure 1a, has a narrow crossover of $8 \mathrm{~km}$ in the western basin of Chibuzhang Co. Even though an $8 \mathrm{~km}$-wide water channel is sufficient in earlier studies to pick points for altimetry estimates, in this case the distance to the contiguous land in northeast and west is less than $5 \mathrm{~km}$ along the entire crossover. The formation of terrain induces severe land contamination in the waveform; thus, the height measurements are problematic and need further sophisticated retracking algorithms. The underperformance of Envisat at this crossover is also seen in the comparison with ICESat and 
Jason-2 data, with RMSDs ranging between 0.54 and $0.68 \mathrm{~m}$ and CCs between 0.93 and 0.57 , which are generally worse than TIAS results. To conclude, TIAS is a reliable water level estimate approach in this study site because the RMSD values, as compared with ICESat and Jason-2, are in 0.30-0.49 m level while the CC are higher than 0.90 .

\subsection{Quantification of Water Volume Change}

The quantification of water mass change is calculated through TIAS estimates and SRTM, and compared with GRACE gravity field solutions. The water volume estimated by TIAS includes column water from the bottom of a modified SRTM up to the water surface in each pixel. However, because the depth of the simulated lake bottom contains large errors, we only quantify relative volume changes in 2002-2015, by subtracting the mean value of volumes over the time series span. The TIAS, plotted as a red line with dots in Figure 6, is the mass change of a combined contribution from Chibuzhang Co and Dorsoidong Co since 2002. It is converted into EWH over a $2^{\circ}$ square that matches the same expression with GRACE result. First, it is observed that in 2002-2015 the lake mass change has a nearly consistent rate at $+0.89 \pm 0.05 \mathrm{~cm} \cdot \mathrm{yr}^{-1}(95 \% \mathrm{CI})$ from TIAS-converted $\mathrm{EWH}$, regardless of the interconnection between lakes. To compare with a synoptic view of mass change offered by GRACE, the blue line with dots is an average taken from JPL/CSR/GFZ solutions, where the error bar is the standard deviation of the three. A blue fitting line in the middle indicates that the increasing trend from GRACE data is slower at $+0.41 \pm 0.17 \mathrm{~cm} \cdot \mathrm{yr}^{-1}(95 \% \mathrm{CI})$, where light blue and gray shades display $95 \%$ and $99 \%$ of fitting confidence interval, respectively. This result suggests that this twin lake plays an important role in the mass change of surrounding areas, in accordance with previous investigation [7]. However, by looking at the time series itself the GRACE seems to experience higher variability than the TIAS solution. We assume the majority of the GRACE signal within this region is driven by water storage in snow, surface water, soil moisture, and effects from local glacier systems. This would cause the GRACE signal to have a higher fluctuation compared to the lake system alone.

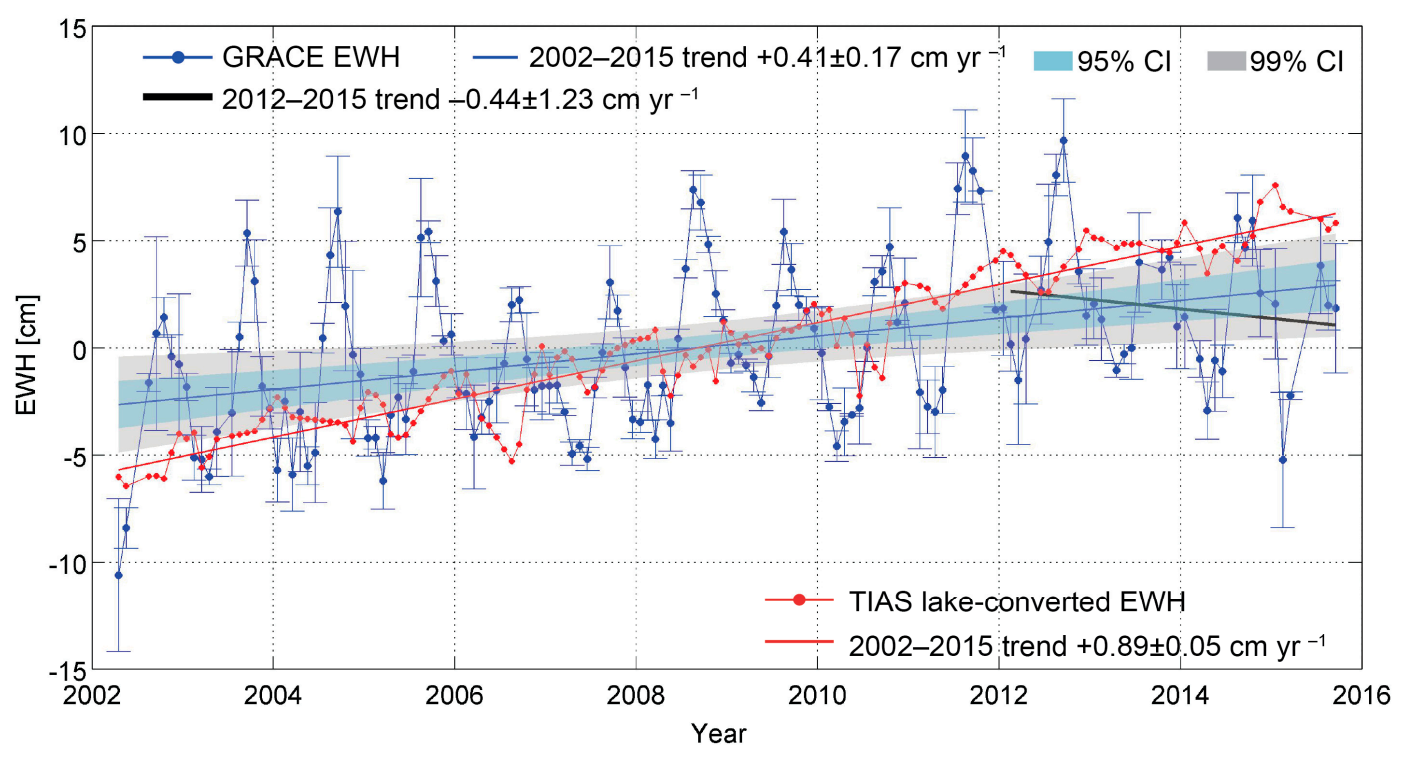

Figure 6. TIAS water mass anomaly compared with GRACE data centered at the study site.

\section{Discussions}

Based on [6], there is still about $40 \%$ of mass changes remain unexplained or technically inseparable from factors abovementioned. Thus we could propose a scenario based on this evidence. For example, the rising red line turned from sharp to gradual after lake connection in Figure 3, while the blue line turned from stable to increase. Dorsoidong Co seems to dominate most of the mass change in this area. We suspect that the water mass, except for precipitation that contributes to both 
lakes, is more from Purog Kangri on the west side than Gêladaindong on the east. This result also implies the glacier depletion from Purog Kangri is probably faster than from Gêladaindong. However, this theory is valid only if the mass loss in each glacier system contributes equal percentage toward this twin lake area, which requires further study about contributing glaciers and surface runoff.

Another possibility causing the changing pattern in Figures 3 and 6 is a long-term unbalance of rainfall in this area, e.g., more input from the west. By checking the rainfall record provided by TRMM 3B43 product, as shown in Figure 7, we notice that the rainfall rate on either side of this twin lake is quite similar since the beginning of TRMM record in 1998. The blue line and red line indicate daily rainfall rate roughly within the basin of Chibuzhang Co and Dorsoidong Co, respectively. In most years, such as 2003, 2004, 2008, 2013, and 2014, the daily rainfall rate in peak months is even larger in the basin of Chibuzhang Co than that of Dorsoidong. Only in 2002 and 2005, the rainfall rates from the west have anomalous peaks. In most years, the rainfall pattern is nearly identical over this semi-arid central of TP. Therefore, the mass change, especially the contrasting pattern of water volume increase in this twin lake, is less disturbed by the factor of rainfall. This result supports the discussion in [6]: the glacier meltwater augmented the precipitation-driven lakes near the central TP.

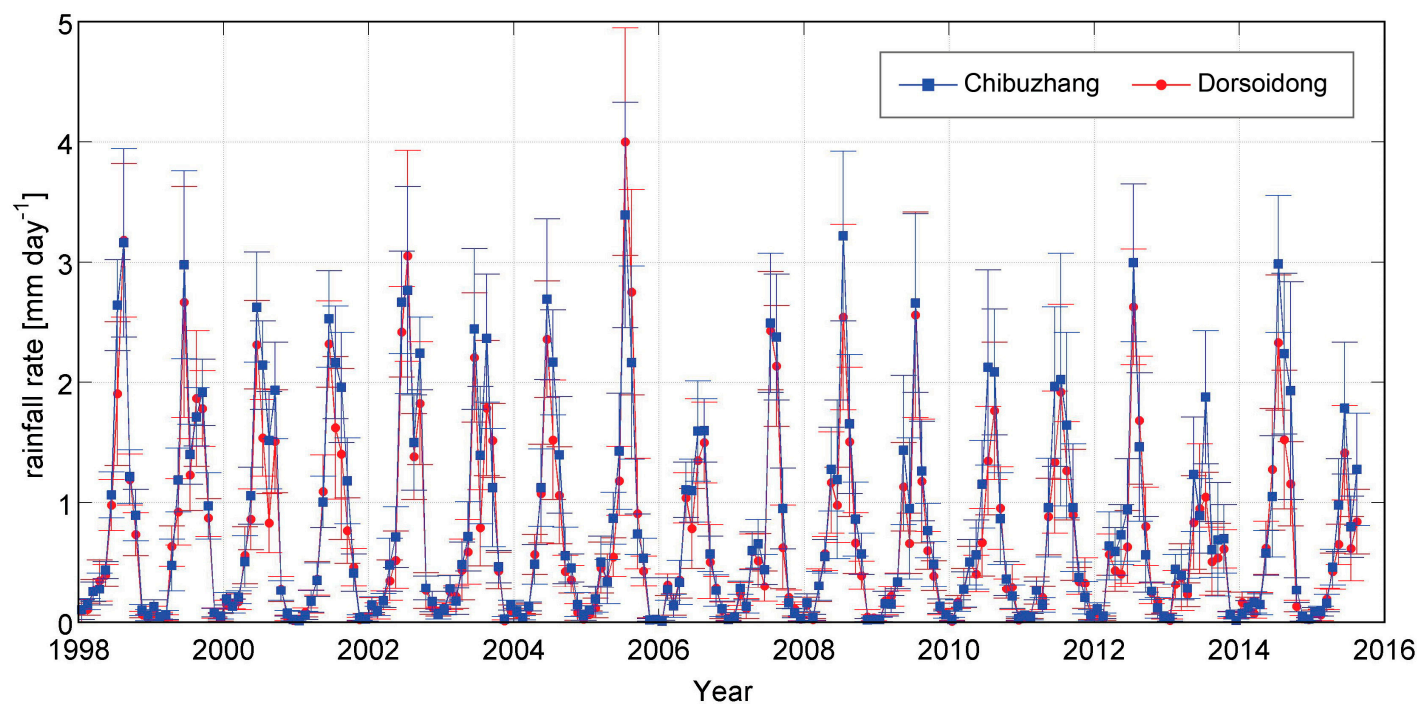

Figure 7. TRMM monthly solution of daily rainfall rate in two spatial boxes specified in Section 3.5. The blue line is for Chibuzhang Co and red line is for Dorsoidong Co. Error bars were computed from $1 \sigma$ of 16 grid values on each side.

Another interesting pattern in Figure 5 is the overturning trend of GRACE data after 2012. Comparing with a positive trend at $+0.41 \pm 0.17 \mathrm{~cm} \cdot \mathrm{yr}^{-1}$ over the entire time span, the trend in the last four years (2012-2015) actually downturns to a negative value at $-0.44 \pm 1.23 \mathrm{~cm} \cdot \mathrm{yr}^{-1}$. Note that this downward trend, although visually detectable from figures, still contains large uncertainty due to short time span and seasonality. However, in contrast, all altimetry data sets show consistent rising pattern during 2012-present, we are confident the mass contribution from this twin lake has no significant drainage in the same period. However, without sufficient knowledge about ground water and other hydrological/geophysical parameters, the cause of this reverse trend remains uncertain. Again, the GRACE signal includes total water storage within a region that includes many other factors than just lake water. Nevertheless, the regional scale of changes including glacier depletion in this area can only be understood from the GRACE data at the current stage.

\section{Conclusions}

The lake change pattern of two major lakes, Chibuzhang Co and Dorsoidong Co, in the central TP is separately observed by a variety of independent spaceborne sensors. The TIAS proved to be useful 
to fill spatial/temporal gaps between altimetry ground tracks and missions, to serve as complementary data for water level observations. In this research, the TIAS method unveils the water level change before and after interlink of these two lakes. Together with other measurements, such as ICESat, Jason-2, and Envisat, we observe an increase of this twin lake, especially after 2000. The volume change is also estimated through a combination with the SRTM DEM. Although the scale and sensing parameters may not be equivalent, GRACE gravimetry is also employed here to provide a reference of mass change in the neighborhood of $2^{\circ}$. The high variability in the GRACE time series compared to the lake level time series suggests other hydrologic components are incorporated in the gravity signal. However, because this twin lake is one of the major mass sources in this area [7], it is worth inspecting the temporal change from GRACE gravity anomaly. The trend of mass change is fairly consistent between TIAS and GRACE derived EWH in 2002-2015. In contrast, the GRACE data shows a short-term downward trend since 2012 but the pattern has not been seen in lake volume. This trend is visually observable, but insignificant, at this moment due to the short time span. The reason that causes a recent down-turning of mass change in the GRACE data remains elusive since no significant anomaly in precipitation has been reported after 2012. The cause of such a momentum to reverse the trend is interesting and worth overseeing further development. In future studies, inclusion of other data products, such as large-scale land cover monitored by the Moderate Resolution Imaging Spectroradiometer (MODIS), or the surface/subsurface condition provided by the Global Land Data Assimilation System (GLDAS), would be helpful to bridge the gaps between data used currently.

Acknowledgments: This work was supported in part by the Ministry of Science and Technology (MOST), Taiwan, under project 104-2119-M-008-005-MY2 and 104-2221-E-008-099-MY3, in part by the National Central University New Faculty Research Award. Chungyen Kuo was also partially supported by the Headquarters of University Advancement at National Cheng Kung University, Taiwan. We thank NASA, ESA, and CNES for providing the radar altimeter data, and NASA and USGS for providing the Landsat data used in this study.

Author Contributions: Kuo-Hsin Tseng is the primary author who established the concept of the presented study. He performed the processing of the used remote sensing data including Landsat time series analysis as well as spatial-temporal analysis based on the TIAS workflow. Chung-Pai Chang provided an overview of geophysics and climatology of the TP. C.K. Shum and Kun Shang performed the analysis of GRACE and comparison with other data sets. Chung-Yen Kuo and Kuan-Ting Liu was responsible for extracting altimetric height from Envisat and Jason-2 data record. Yuanyuan Jia and Jian Sun performed Landsat imageries pre-processing and validation with other data sources.

Conflicts of Interest: The authors declare no conflict of interest.

\section{References}

1. Fang, Y.; Cheng, W.; Zhang, Y.; Wang, N.; Zhao, S.; Zhou, C.; Chen, X.; Bao, A. Changes in inland lakes on the Tibetan Plateau over the past 40 years. J. Geogr. Sci. 2016, 26, 415-438. [CrossRef]

2. Khandu, K.; Forootan, E.; Schumacher, M.; Awange, J.L.; Müller Schmied, H. Exploring the influence of precipitation extremes and human water use on total water storage (TWS) changes in the Ganges-Brahmaputra-Meghna River Basin. Water Resour. Res. 2016, 52, 2240-2258. [CrossRef]

3. Liu, X.; Chen, B. Climatic warming in the Tibetan Plateau during recent decades. Int. J. Climatol. 2000, 20, 1729-1742. [CrossRef]

4. Xu, B.; Cao, J.; Hansen, J.; Yao, T.; Joswia, D.R.; Wang, N.; Wu, G.; Wang, M.; Zhao, H.; Yang, W.; et al. Black soot and the survival of Tibetan glaciers. Proc. Natl. Acad. Sci. USA 2009, 106, 22114-22118. [CrossRef] [PubMed]

5. Tseng, K.H.; Shum, C.K.; Lee, H.; Duan, J.B.; Kuo, C.Y.; Song, S.L.; Zhu, W.Y. Satellite observed environmental changes over the Qinghai-Tibetan Plateau. Terr. Atmos. Ocean. Sci. 2011, 22, 229-239. [CrossRef]

6. Song, C.; Huang, B.; Richards, K.; Ke, L.; Hien Phan, V. Accelerated lake expansion on the Tibetan Plateau in the 2000s: Induced by glacial melting or other processes? Water Resour. Res. 2014, 50, 3170-3186. [CrossRef]

7. Zhang, G.; Yao, T.; Xie, H.; Kang, S.; Lei, Y. Increased mass over the Tibetan Plateau: From lakes or glaciers? Geophys. Res. Lett. 2013, 40, 2125-2130. [CrossRef]

8. Tapley, B.D.; Bettadpur, S.; Ries, J.C.; Thompson, P.F.; Watkins, M.M. GRACE measurements of mass variability in the Earth system. Science 2004, 305, 503-505. [CrossRef] [PubMed] 
9. Moore, P.; Williams, S.D.P. Integration of altimetric lake levels and GRACE gravimetry over Africa: Inferences for terrestrial water storage change 2003-2011. Water Resour. Res. 2014, 50, 9696-9720. [CrossRef]

10. Medina, C.; Gomez-Enri, J.; Alonso, J.J.; Villares, P. Water volume variations in Lake Izabal (Guatemala) from in situ measurements and ENVISAT Radar Altimeter (RA-2) and Advanced Synthetic Aperture Radar (ASAR) data products. J. Hydrol. 2010, 382, 34-48. [CrossRef]

11. Baup, F.; Frappart, F.; Maubant, J. Combining high-resolution satellite images and altimetry to estimate the volume of small lakes. Hydrol. Earth Syst. Sci. 2014, 18, 2007-2020. [CrossRef]

12. Tseng, K.H.; Shum, C.K.; Kim, J.W.; Wang, X.; Zhu, K.; Cheng, X. Integrating Landsat Imageries and Digital Elevation Models to Infer Water Level Change in Hoover Dam. IEEE J. Sel. Top. Appl. Earth Obs. Remote Sens. 2015, 1-14. [CrossRef]

13. Song, C.; Sheng, Y. Contrasting evolution patterns between glacier-fed and non-glacier-fed lakes in the Tanggula Mountains and climate cause analysis. Clim. Chang. 2015, 135, 493-507. [CrossRef]

14. Zhang, P.Z.; Shen, Z.; Wang, M.; Gan, W.; Bürgmann, R.; Molnar, P.; Wang, Q.; Niu, Z.; Sun, J.; Wu, J.; et al . Continuous deformation of the Tibetan Plateau from global positioning system data. Geology 2004, 32, 809-812. [CrossRef]

15. Zhang, J.; Braaten, D.A.; Li, X.; Tao, F. An Inventory of Glacier Changes between 1973 and 2011 for the Geladandong Mountain Area, China; European Geosciences Union: Munich, Germany, 2013.

16. Ye, Q.; Kang, S.; Chen, F.; Wang, J. Monitoring glacier variations on Geladandong mountain 2013, central Tibetan Plateau, from 1969 to 2002 using remote-sensing and GIS technologies. J. Glaciol. 2006, 52, 537-545. [CrossRef]

17. Zhang, Y.; Yao, T.; Ma, Y. Climatic changes have led to significant expansion of lakes in Xizang (Tibet) since 1995. Sci. Cold Arid Reg. 2011, 3, 463-467.

18. Zhang, Y.; Liu, S.Y.; Xu, J.L.; Shangguan, D.H. Glacier change and glacier runoff variation in the Tuotuo River basin, the source region of Yangtze River in western China. Environ. Geol. 2008, 56, 59-68. [CrossRef]

19. Pfeffer, W.T.; Arendt, A.A.; Bliss, A.; Bolch, T.; Cogley, J.G.; Gardner, A.S.; Hagen, J.O.; Hock, R.; Kaser, G.; Kienholz, C.; et al. The Randolph Glacier Inventory: A globally complete inventory of glaciers. J. Glaciol. 2014, 60, 537-552. [CrossRef]

20. Brown, G.S. The average impulse response of a rough surface and its applications. IEEE Trans. Antennas Propag. 1977, 25, 67-74. [CrossRef]

21. Van der Veen, C.J. Interpretation of short-term ice-sheet elevation changes inferred from satellite altimetry. Clim. Chang. 1993, 23, 383-405. [CrossRef]

22. Ekholm, S.; Forsberg, R.; Brozena, J.M. Accuracy of satellite altimeter elevations over the Greenland ice sheet. J. Geophys. Res. Oceans 1995, 100, 2687-2696. [CrossRef]

23. Kouraev, A.V.; Semovski, S.V.; Shimaraev, M.N.; Mognard, N.M.; Légresy, B.; Remy, F. Observations of Lake Baikal ice from satellite altimetry and radiometry. Remote Sens. Environ. 2007, 108, 240-253. [CrossRef]

24. Tseng, K.H.; Shum, C.K.; Yi, Y.; Emery, W.J.; Kuo, C.Y.; Lee, H.; Wang, H. The improved retrieval of coastal sea surface heights by retracking modified radar altimetry waveforms. IEEE Trans. Geosci. Remote Sens. 2014, 52, 991-1001. [CrossRef]

25. Berry, P.A.M.; Garlick, J.D.; Freeman, J.A.; Mathers, E.L. Global inland water monitoring from multi-mission altimetry. Geophys. Res. Lett. 2005, 32. [CrossRef]

26. Lee, H.; Shum, C.K.; Tseng, K.H.; Huang, Z.; Sohn, H.G. Elevation changes of Bering Glacier System, Alaska, from 1992 to 2010, observed by satellite radar altimetry. Remote Sens. Environ. 2013, 132, 40-48. [CrossRef]

27. Liu, G.; Schwartz, F.W.; Tseng, K.H.; Shum, C.K. Discharge and water-depth estimates for ungauged rivers: Combining hydrologic, hydraulic, and inverse modeling with stage and water-area measurements from satellites. Water Resour. Res. 2015, 51, 6017-6035. [CrossRef]

28. Uebbing, B.; Kusche, J.; Forootan, E. Waveform retracking for improving level estimations from TOPEX/Poseidon, Jason-1, and Jason-2 Altimetry Observations over African Lakes. IEEE Trans. Geosci. Remote Sens. 2015, 53, 2211-2224. [CrossRef]

29. Kuo, C.Y.; Cheng, Y.J.; Lan, W.H.; Kao, H.C. Monitoring Vertical Land Motions in Southwestern Taiwan with Retracked Topex/Poseidon and Jason-2 Satellite Altimetry. Remote Sens. 2015, 7, 3808-3825. [CrossRef]

30. Shum, C.K.; Ries, J.C.; Tapley, B.D. The accuracy and applications of satellite altimetry. Geophys. J. Int. 1995, 121, 321-336. [CrossRef] 
31. Tseng, K.H.; Shum, C.K.; Yi, Y.; Fok, H.S.; Kuo, C.Y.; Lee, H.; Cheng, X.; Wang, X. Envisat altimetry radar waveform retracking of quasi-specular echoes over the ice-covered Qinghai lake. Terr. Atmos. Ocean. Sci. 2013, 24, 615-627. [CrossRef]

32. Kuo, C.Y.; Kao, H.C. Retracked Jason-2 altimetry over small water bodies: Case study of Bajhang River, Taiwan. Mar. Geod. 2011, 34, 382-392. [CrossRef]

33. Sulistioadi, Y.B.; Tseng, K.H.; Shum, C.K.; Hidayat, H.; Sumaryono, M.; Suhardiman, A.; Setiawan, F.; Sunarso, S. Satellite radar altimetry for monitoring small rivers and lakes in Indonesia. Hydrol. Earth Syst. Sci. 2015, 19, 341-359. [CrossRef]

34. Zelli, C. ENVISAT RA-2 advanced radar altimeter: Instrument design and pre-launch performance assessment review. Acta Astronaut. 1999, 44, 323-333. [CrossRef]

35. Frappart, F.; Calmant, S.; Cauhopé, M.; Seyler, F.; Cazenave, A. Preliminary results of ENVISAT RA-2-derived water levels validation over the Amazon basin. Remote Sens. Environ. 2006, 100, 252-264. [CrossRef]

36. Khaki, M.; Forootan, E.; Sharifi, M.A. Satellite radar altimetry waveform retracking over the Caspian Sea. Int. J. Remote Sens. 2014, 35, 6329-6356. [CrossRef]

37. Guo, J.; Chang, X.; Gao, Y.; Sun, J.; Hwang, C. Lake level variations monitored with satellite altimetry waveform retracking. IEEE J. Sel. Top. Appl. Earth Obs. Remote Sens. 2009, 2, 80-86. [CrossRef]

38. Lee, H.; Shum, C.K.; Tseng, K.H.; Guo, J.Y.; Kuo, C.Y. Present-day lake level variation from ENVISAT Altimetry over the northeastern Qinghai-Tibetan Plateau: Links with precipitation and temperature. J. Terr. Atmos. Ocean Sci. 2011, 22, 169-175. [CrossRef]

39. Lambin, J.; Morrow, R.; Fu, L.L.; Willis, J.K.; Bonekamp, H.; Lillibridge, J.; Perbos, J.; Zaouche, G.; Vaze, P.; Bannoura, W.; et al. The OSTM/Jason-2 mission. Mar. Geod. 2010, 33, 4-25. [CrossRef]

40. Schutz, B.E.; Zwally, H.J.; Shuman, C.A.; Hancock, D.; DiMarzio, J.P. Overview of the ICESat mission. Geophys. Res. Lett. 2005, 32. [CrossRef]

41. Abshire, J.B.; Sun, X.; Riris, H.; Sirota, J.M.; McGarry, J.F.; Palm, S.; Yi, D.; Liiva, P. Geoscience laser altimeter system (GLAS) on the ICESat mission: On-orbit measurement performance. Geophys. Res. Lett. 2005, 32, L21S02. [CrossRef]

42. NASA's Earth Observing System Clearing House (ECHO) Online Portal. Available online: http:// reverb. echo.nasa.gov (accessed on 10 May 2016).

43. EarthExplorer. Available online: http:/ / earthexplorer.usgs.gov (accessed on 10 May 2016).

44. Chander, G.; Markham, B.L.; Helder, D.L. Summary of current radiometric calibration coefficients for Landsat MSS, TM, ETM+, and EO-1 ALI sensors. Remote Sens. Environ. 2009, 113, 893-903. [CrossRef]

45. USGS. Using the USGS Landsat 8 Product. Available online: http://landsat.usgs.gov/Landsat8_Using_ Product.php (accessed on 10 May 2016).

46. Burns, P.; Nolin, A. Using atmospherically-corrected Landsat imagery to measure glacier area change in the Cordillera Blanca, Peru from 1987 to 2010. Remote Sens. Environ. 2014, 140, 165-178. [CrossRef]

47. Singh, A. Review article digital change detection techniques using remotely-sensed data. Int. J. Remote Sens. 1989, 10, 989-1003. [CrossRef]

48. $\mathrm{Xu}, \mathrm{H}$. Modification of normalized difference water index (NDWI) to enhance open water features in remotely sensed imagery. Int. J. Remote Sens. 2006, 27, 3025-3033. [CrossRef]

49. McFeeters, S.K. The use of the Normalized Difference Water Index (NDWI) in the delineation of open water features. Int. J. Remote Sens. 1996, 17, 1425-1432. [CrossRef]

50. Ries, J.C.; Bettadpur, S.; Poole, S.; Richter, T. Mean background gravity fields for GRACE processing. In Proceedings of the GRACE Science Team Meeting, Austin, TX, USA, 8-10 August 2011.

51. Duan, X.J.; Guo, J.Y.; Shum, C.K.; Van Der Wal, W. On the postprocessing removal of correlated errors in GRACE temporal gravity field solutions. J. Geod. 2009, 83, 1095-1106. [CrossRef]

52. Guo, J.Y.; Duan, X.J.; Shum, C.K. Non-isotropic Gaussian smoothing and leakage reduction for determining mass changes over land and ocean using GRACE data. Geophys. J. Int. 2010, 181, 290-302. [CrossRef]

53. Cheng, M.K.; Tapley, B.D.; Ries, J.C. Deceleration in the Earth's oblateness. J. Geophys. Res. 2013, 118, 1-8. [CrossRef]

54. Swenson, S.; Chambers, D.; Wahr, J. Estimating geocenter variations from a combination of GRACE and ocean model output. J. Geophys. Res. Solid Earth 2008, 113, B08410. [CrossRef] 
55. Ivins, E.R.; James, T.S.; Wahr, J.; Schrama, E.J.O.; Landerer, F.W.; Simon, K.M. Antarctic contribution to sea level rise observed by GRACE with improved GIA correction. J. Geophys. Res. Solid Earth 2013, 118, 3126-3141. [CrossRef]

56. Forootan, E.; Kusche, J.; Loth, I.; Schuh, W.D.; Eicker, A.; Awange, J.; Longuevergne, L.; Diekkrüger, B.; Schmidt, M.; Shum, C.K. Multivariate prediction of total water storage changes over West Africa from multi-satellite data. Surv. Geophys. 2014, 35, 913-940. [CrossRef]

57. Huffman, G.J.; Bolvin, D.T.; Nelkin, E.J.; Wolff, D.B.; Adler, R.F.; Gu, G.; Hong, Y.; Bowman, K.P.; Stocker, E.F. The TRMM multisatellite precipitation analysis (TMPA): Quasi-global, multiyear, combined-sensor precipitation estimates at fine scales. J. Hydrometeorol. 2007, 8, 38-55. [CrossRef]

(C) 2016 by the authors; licensee MDPI, Basel, Switzerland. This article is an open access article distributed under the terms and conditions of the Creative Commons Attribution (CC-BY) license (http://creativecommons.org/licenses/by/4.0/). 